\title{
A NOVEL NANOGEL FORMULATION OF FINASTERIDE FOR TOPICAL TREATMENT OF ANDROGENETIC ALOPECIA: DESIGN, CHARACTERIZATION AND IN VITRO EVALUATION
}

\author{
DIVYA SANGANABHATLA*, R. SHYAM SUNDER
}

Department of Pharmacy, University College of Technology, Osmania University, Hyderabad 500007, India

*Email: divya.dharba@gmail.com

Received: 25 Mar 2021 Revised and Accepted: 02 Jun 2021

\begin{abstract}
Objective: The present paper describes the development and evaluation of a Novel Finasteride (FSD) nanogel topical delivery for the treatment of Androgenetic Alopecia. Nano-based topical formulation was chosen to enhance the solubility, permeability, biocompatibility of drug and to overcome the problems associated with the oral delivery of finasteride.

Methods: Various trails batches were prepared by using probe sonication method. Based on stability studies and particle size, NP4 trail was optimized which exhibited a spherical shape with a mean diameter of $113.80 \pm 0.72$, the polydispersity of $0.28 \pm 0.01$, zeta potential of- $25.2 \mathrm{mV}$, drug entrapment efficiency of $92.67 \pm 0.47 \%$, and drug loading of $6.15 \pm 0.02 \%$. Storage stability studies demonstrated that the particle size and entrapment efficiency were not changed during 3 mo both at $4{ }^{\circ} \mathrm{C}$ and room temperature. Finasteride (FSD) NLCs were characterized for particle size by scanning electron microscope (SEM), chemical state by X-Ray diffraction (XRD), physical stability by centrifugation and thermodynamic stability by Freeze-thaw method. These prepared nanoparticles were transformed into topical nanogel and further evaluated.
\end{abstract}

Results: Among the different trails, C2 trail of NLC gel has shown excellent gelling capacity, clear appearance, good viscosity characteristics and was selected for further evaluation studies. Batches of topical nanogel were characterized through pH, homogeneity, spreadability, viscosity, drug content and in vitro drug release study. Based on $\mathrm{pH}(6.5-6.8)$, drug content (91.25 $\pm 0.9 \%)$, spreadability (6.7 cm/sec), C2 batch was subjected to In vitro skin occlusivity study, in-vitro release study and In vitro heamolysis study.

Conclusion: The percent cumulative drug release for Finasteride (FSD) gel was found to be $758.52 \pm 1.49 \mu \mathrm{g}$ at $24 \mathrm{~h}$ which is quite higher than plain gel and Finasteride (FSD) gel showed maximum occlusiveness and excellent spreadability and found to be stable. In conclusion, prepared Finasteride (FSD) Nanogel could be used with promising potential for the treatment of Androgenetic Alopecia.

Keywords: Nanoparticles (NP), Androgenetic alopecia, Nano lipid carrier (NLC), Finasteride (FSD)

(C) 2021 The Authors. Published by Innovare Academic Sciences Pvt Ltd. This is an open access article under the CC BY license (https://creativecommons.org/licenses/by/4.0/)

DOI: https://dx.doi.org/10.22159/ijap.2021v13i4.41599. Journal homepage: https://innovareacademics.in/journals/index.php/ijap

\section{INTRODUCTION}

Androgenetic alopecia (AGA) is a common chronic, dermatological condition in both men and women characterized by a hereditary inheritance pattern, beginning with the advent of puberty where scalp hair progressively thins in a defined pattern in the temporal region, progressive miniaturization of the hair follicle and shaft. Androgenetic alopecia is an extremely common dermatological disorder affecting both men and women. This disease is characterized by a reduction of frontal hair in temporal region, resulting in a gradual decrease in the hair diameter [1]. Oral finasteride (FSD), a synthetic 4-aza-3oxosteroid compound with poor aqueous solubility, blocks the peripheral conversion of testosterone to dihydrotestosterone (DHT) by inhibiting $5 \alpha$ reductase at TRP56 [2], which results in a significant reduction of DHT concentration and achieving satisfactory results in alopecia treatment. However, its oral intake generally causes severe side effects such as "gynecomastia, breast tenderness, malignant neoplasms of the male breast, decreased ejaculate volume, decrease in testicular size, testicular pain, reduction in penile curvature, reduction in penile size, sexual disorder, male infertility, high-grade prostate cancer, and prostatitis" have been reported [3]. Considering that there is currently no scientifically proven treatment, new drug delivery systems able to improve alopecia therapy are urgently required. Therefore, it is necessary to find another route to administer FSD into the system without those adverse side effects. On the other hand, most topical products available in the market for alopecia are mostly wateralcohol solutions [4] and liposomal formulations. There is a drawback in using water-alcohol solutions, as only a fraction of the applied drug dose actually reaches the target site, it shows low permeability through the keratin layer. As a result, those products do not meet the expectations of consumer, due to lack of adherence to treatment and the drawbacks of utilizing conventional liposomes in transdermal delivery, as they are trapped in the upper skin layers, have been previously reported [5]. Nanoparticles are one of the novel liposomes which have been used to improve drug delivery. Recent studies have confirmed the hypothesis that nanoparticles can penetrate effectively and remain in the pilous follicles for longer periods [6]. Nanoparticles is a novel approach having several advantages in achieving solubilization of hydrophobic drugs, reduction of a drug dose used and, in some cases, prevention or elimination of side effects [7-9]. The present study aims for the preparation and evaluation of FSD-loaded nanoparticles formula and incorporation of the same into gel for the treatment of androgenetic alopecia. Characterization of nanoparticles was performed by using SEM, microscopic examination, zeta potential, size distribution, encapsulation efficiency (EE), particle size and loading capacity. Physical properties of nanoparticles loaded gel were evaluated such as organoleptic characters, spreadability, viscosity, $\mathrm{pH}$ and drug content uniformity. Further, studied in vitro drug release by dialysis membrane, skin occlusivity test and hemolysis test.

\section{MATERIALS AND METHODS}

Finasteride and other chemicals were procured from Yarrochem products, Mumbai, India. All other reagents were of analytical grade. Effects of various excipients on the incompatibility, entrapment efficiency, drug release, percutaneous absorption, stability studies were evaluated. Characterization of ethosomes was performed by using SEM, micorscopic examination, zetapotential and size distribution. Physical properties of ethosomal gel were evaluated such as organoleptic characters, washability, spreadability, viscosity, $\mathrm{pH}$ and drug content uniformity. Further.

\section{Method for development of finasteride formulation \\ Formulation screening}

The method of formulation screening was based on solubility and partitioning behavior between different solid lipids and liquid lipid and surfactant to be used in the formulation. 


\section{Screening of lipids}

Solubility of the drug in a lipid is a key factor to achieve high entrapment of the drug into the lipid matrix. Therefore, the solubility of drug in various lipids was determined in order to determine the lipid having a maximum potential to solubilize the drug. Selection of solid lipid for the production of Nanostructured lipid carriers was carried out by employing a method similar to studies suggested by Franklin [10]. The fixed amount of FSD (50 mg) was taken in a test tube and to it solid lipid such as Glycerol Monostearate (GMS), Carnauba wax, stearic acid, Bees wax, Soya lecithin in increments of $0.5 \mathrm{~g}$ was continuously added. The test tube was heated in a controlled temperature water bath kept at 80 ${ }^{\circ} \mathrm{C}$. The endpoint of the solubility study was the formation of clear, yellowish-white solution of molten lipid. The amount of lipid required to solubilize the FSD completely in molten state was estimated.

\section{Screening of surfactant and liquid lipid system}

One of the most important factors that determine the loading capacity of the drug in the lipid is the solubility of drug in melted lipid. Solubility study of FSD was determined in various surfactants such as Tween 20, Tween 80, Cremophore RH40, Labrasol and in various liquid lipid such as Capmul MCM, Captex, Oleic acid, Transcutol HP etc. Excess drug was added to a known volume of the solvent and liquid systems and mixed for 2 min and sonicated for 10 min to dissolve the FSD. Incubator shaker was further used for 8-12 $\mathrm{h}$ to dissolve the FSD. The contents were then centrifuged at $5000 \mathrm{rpm}$ for $15 \mathrm{~min}$ (Remi Laboratory instruments). The aliquots of supernatant were diluted appropriately and analyzed using a UV spectrophotometer at $255 \mathrm{~nm}$ [11]. Tween 80 showed solubility of FSD at $415.18 \mathrm{mg} / \mathrm{ml}$ and Transcutol HP showed solubility of FSD at $420.65 \mathrm{mg} / \mathrm{ml}$. Therefore, these excipients are selected for further studies.

\section{Screening of process parameters}

\section{Partition study}

Although drug having high solubility in lipid may precipitate out into aqueous media In vivo, if its partition coefficient (PC) is low. It is necessary to perform the partition study of drug between lipid and aqueous media. In this study, $10 \mathrm{mg}$ of FSD was dispersed in a mixture of melted lipid ( $1 \mathrm{~g})$ and hot distilled water $(1 \mathrm{ml})$ and shaken for $30 \mathrm{~min}$ in hot water bath. After shaking for $30 \mathrm{~min}$, the mixture was centrifuged at $2000 \mathrm{rpm}$ for $30 \mathrm{~min}$ at $25^{\circ} \mathrm{C}$ to separate lipid (Remi/R-8C Laboratory instrument). The supernatant (aqueous phase) was taken, diluted appropriately and analyzed by UV spectrophotometer to determine the amount of FSD in the aqueous phase. Results demonstrated that FSD had higher partitioning in GMS and Transcutol HP, compared to other solid and liquid lipids respectively and were chosen as solid lipid and liquid lipid respectively for development of NLCs [12].

The partition coefficient (PC) was calculated by the equation given below:

$$
\mathrm{PC}=\frac{\mathrm{Ai}-\mathrm{Aw}}{\mathrm{Aw}}
$$

Where,

\section{$A_{i}$ is initial amount of FSD taken (50 mg)}

Aw is the amount of FSD in the aqueous phase

\section{Compatibility study of solid and liquid lipids}

After selection of solid lipid and liquid lipid a compatibility study of both lipids were performed. Selected solid lipids and liquid lipids were taken in the ratios $9: 1,7: 3$, and 3:1. Mixtures were heated up to $10{ }^{\circ} \mathrm{C}$ more than the melting point of the solid lipid in glass vials and then checked after $1 \mathrm{~h}$ for homogeneity, immediately after solidification and after $24 \mathrm{~h}$. Mixtures with only one single phase were selected for further study [13].

\section{Formulation of finasteride loaded nanostructured lipid carrier (FSD-NLC)}

FSD-NLCs were formulated using selected solid lipid, liquid lipid and surfactant in a different ratio. FSD-NLCs were prepared employing a simple and reproducible probe sonication method. In this method two phases i.e., lipid and aqueous phase made separately. In lipid phase, solid lipid, liquid lipid, surfactant and drug (dissolved separately in methanol) were melted at a temperature $10^{\circ} \mathrm{C}$ above the melting point of solid lipid to get clear solution. The melted lipid phase was dispersed in an aqueous solution which was kept at the same temperature to form pre-emulsion. This pre-emulsion was stirred at $1000 \mathrm{rpm}$ for $10 \mathrm{~min}$ and the temperature was maintained at $65{ }^{\circ} \mathrm{C}-70{ }^{\circ} \mathrm{C}$ to get homogeneous mixture. Further, this pre-emulsion was subjected to ultrasonication using probe sonicator (Leela sonic Industries) and then cooled to room temperature to form FSD-NLC dispersion.

\section{Characterization and evaluation of finasteride loaded nano lipid carriers (FSD-NLC)}

\section{Stability of trail batches}

Finasteride trial batches were studied for effect of sonication time and exposed to normal conditions of temperature and humidity (room temperature, ambient relative humidity) to determine whether it renders precipitation or not [14].

\section{Particle size determination}

Mean particle size and size distribution was measured by photon correlation spectroscopy using Nanophox Symphatech GmbH, Germany, at room temperature. Before measurement, batches were diluted with filtered double distilled water until the appropriate concentration of particles was achieved to avoid multi scattering events. On the basis of particle size, the batch which shows least particle size and good stability was selected for further preparations [15].

\section{Sonication time}

Sonication time was considered for evaluation as it affects the particle size of NLCs. The selected batch was subjected to ultrasonication to check the effect of sonication time. Time points such as; 5, 10, 15 and $20 \mathrm{~min}$ were selected and at each time point samples were withdrawn. These samples were evaluated for particle size and polydispersity index and on the basis of minimum particle size obtained at least time point, which was considered as sonication time for further formulations of NLCs.

\section{Characterization of nano lipid carrier dispersion}

\section{Particle size and polydispersity index distribution}

Particle size and Polydispersity index (PDI) which is a measure of the distribution of nanoparticle population were determined by using Malvern Mastersizer 2000MU (Malvern instrument UK detection limit $0.01-1,000 \mu \mathrm{m}$ ). The obtained data were evaluated using the volume distribution (d10\%, d50\%, d90\%) which means that if the diameter $90 \%(\mathrm{~d} 90 \%)$ is registered as $1 \mu \mathrm{m}$, this indicates that $90 \%$ of particles have a diameter of $1 \mu \mathrm{m}$ or lower [16].

The PI was measured by the span which can be calculated from the following equation.

$$
\text { Span }=\frac{D 90 \%-D 10 \%}{D 50 \%}
$$

Where,

D90\% is the particle diameter at $90 \%$ cumulative size

$\mathrm{D} 10 \%$ is the particle diameter at $10 \%$ cumulative size

D50\% is the particle diameter at $50 \%$ cumulative size

\section{Zeta potential (ZP) measurement}

Zeta potential was determined by measuring the electrophoretic mobility using Malvern Zetasizer Nano ZS 90 (Malvern Instruments, UK). The field strength applied was $20 \mathrm{~V}$-1mPrior to the measurement, all samples were diluted in distilled water.

\section{Scanning electron microscopy}

The morphological characteristics of NLC was studied by scanning electron microscope (JEOL-JSM-6360 JAPAN). One drop of the sample was placed on a slide and excess water was left to dry at room temperature. Further, the slide was attached to the specimen holder using a double-coated adhesive tape and gold-coated under 
vacuum using a sputter coater (Model JFC-1100, Joel, JAPAN) for 10 minutes and investigated at $20 \mathrm{kV}$ [17].

\section{Drug entrapment efficiency and drug loading determination}

A volume of $2.0 \mathrm{ml}$ of each drug-loaded sample was centrifuged at 12500 rpm for $45 \mathrm{~min}$ to separate the lipid and aqueous phase [18]. The supernatant was then diluted with methanol and analyzed by UV-VIS spectrophotometer (UV-1800 Shimadzu spectrophotometer) at $233 \mathrm{~nm}$. The entrapment efficacy of nanoparticles was calculated as follows:

$$
\% \text { Entrapment efficiency }=\frac{W \text { total }-W \text { free }}{W \text { total }} * 100
$$

Where,

EE is entrapment efficiency

\section{DL is Drug loading}

$\mathrm{W}$ total stands for the mass of Finasteride added to the formulation

$\mathrm{W}_{\text {free }}$ is the analyzed weight of drug in the supernatant

\section{Infra-red spectroscopy}

An IR spectrum reveals the characteristic peaks of all functional groups present in a sample. In order to ascertain successful entrapment, the drug, lipid, their physical mixture and NLC were subjected to FTIR studies. IR spectra of FSD, Tween 80 and physical mixture of FSD drug+Tween 80 and Finasteride loaded NLC formulation were recorded using IR Spectrophotometer (Shimadzu model 8400) between the range of $500 \mathrm{~cm}-1$ to $4000 \mathrm{~cm}-1$.

\section{Differential scanning calorimetry studies (DSC)}

DSC analysis of Finasteride, physical mixture of FSD, Tween 80 and NLC formulation were performed using TA DSC Q 20 instrument. The instrument was calibrated with indium. All the samples $(5 \mathrm{mg})$ were heated in aluminum pans using dry nitrogen as the effluent gas. The analysis was performed with a heating range of $20-240{ }^{\circ} \mathrm{C}$ and at a rate of $100 \mathrm{C} /$ minute [19].

\section{$\mathrm{X}$-ray diffractometry (XRD)}

X-ray scattering measurements were carried out using X-ray diffractometer (Shimadzu, XRD-7000). A Cu-Ka radiation source was used with a scanning rate $(2 \mathrm{~h} / \mathrm{min})$ of $5{ }^{\circ} \mathrm{C}$ per min. X-ray diffraction measurements were carried out on Finasteride and SLN dispersion to study its chemical state.

\section{Thermodynamic stability tests}

\section{Centrifugation}

All the chosen formulations were centrifuged at 3500rpm for 30 min. The formulations which have not shown any phase separation was taken for the freeze-thaw cycle test [20].

\section{Freeze-thaw cycle}

All three formulations were kept for $48 \mathrm{~h}$ at the storage temperature of freeze-thaw cycles between-21 ${ }^{\circ} \mathrm{C}$ and $+25^{\circ} \mathrm{C}$. Formulations which passed these thermodynamic stress tests were further taken for the percent transmittance tests for assessing the efficiency of emulsification [21].

Formulation of finasteride loaded nanostructured lipid carriers (FSD-NLCs) based gel

\section{Preparation of nanogel}

Carbopol gel was selected based on the literature and mixed with distilled water and triethanolamine together and kept for continuous mixing using a magnetic stirrer. In the Carbopol gel, the prepared nanoemulsion was added and kept for continuous moving using magnetic stirrer [18].

\section{Method for evaluation of gel}

\section{Physicochemical characteristics of the gel}

\section{Determination of viscosity}

The viscosity of the formulations was determined using Brookfield DVE viscometer. $0.5 \mathrm{~g}$ of the sample was taken for analysis without diluting the sample by using spindle no. 63 at different rpm at $25 \pm 0.5{ }^{\circ} \mathrm{C}[22]$.

\section{Physical appearance and homogeneity}

The final prepared Emulgel formulation was inspected visually for their color intensity variation. All developed gels were tested for homogeneity by visual inspection after the gels have been placed in the container. They were also examined for their appearance and presence of any aggregates [22].

\section{Determination of $\mathrm{pH}$}

The prepared neutral, positive, negative liposomal gels were measured using (Systronics, 361-micro pH meter).

\section{Texture analysis of the gel}

\section{Spreadability}

Spreadability was determined by the apparatus recommended by Multimer which was properly customized in the laboratory and used for the study. It consists of a wooden block provided by a pulley at one end. By this method, spreadability was calculated on the basis of Slip and Drag characteristics of Emulgel [23]. A ground glass slide was fixed on the block. An excess of Emulgel (about 2g) below the study was placed on the ground slide. The Emulgel was then sandwiched between the ground slide and another glass slide having the measurement of the fixed ground slide, provided with the hook. $1 \mathrm{~kg}$ weight was placed on the peak of the two slides for 5 min to expel air and to supply a uniform film of the Emulgel between the slides. Excess of the Emulgel was scrapped off from the edges. The peak plate was then subjected to the weight of $100 \mathrm{~g}$ with the help of string attached to the hook and the time (in seconds) necessary by the peak slide to cover a distance of $7.5 \mathrm{~cm}$ was noted. A shorter interval indicates better spreadability. Spreading coefficient was calculated by using the formula:

$$
S=\frac{M \cdot L}{T}
$$

Where,

$$
\begin{aligned}
& \mathrm{S}=\text { spreadability } \\
& \mathrm{M}=\text { Weight tied to upper slide } \\
& \mathrm{L}=\text { Length of glass slides } \\
& \mathrm{T}=\text { Time taken to separate the slides completely from each other. }
\end{aligned}
$$

\section{Rheological evaluation}

\section{Viscosity studies}

The viscosity of the formulated batches was determined using a Brookfield viscometer with spindle 64 at $10 \mathrm{rpm}$. The assembly was connected to a thermostatically controlled circulating water bath maintained at $25{ }^{\circ} \mathrm{C}$. The formulation whose viscosity was determined was added to a beaker covered with a thermostatic jacket. The spindle was allowed to move freshly into the nanogel and the reading was noted.

\section{Physical appearance and homogeneity}

Physical appearance and homogeneity of gel were observed visually.

\section{PH determination}

The $\mathrm{pH}$ values of $1 \%$ aqueous solutions of the prepared nanogels were measured by a pH meter (Equip-Tronics, EQ 610) [24].

\section{Drug content uniformity}

Drug content was determined by taking $0.2 \mathrm{~g}$ of gel (equivalent to $1 \%$ of the drug) in $10 \mathrm{ml}$ volumetric flask. From this solution, $1 \mathrm{ml}$ was withdrawn and volume adjusted to $10 \mathrm{ml}$ with methanol. The absorbance was taken by UV-Spectrophotometer. Similarly, the content uniformity was determined by analyzing drug concentration in gel taken from 3 to 4 different points from the container [25].

\section{In vitro occlusivity test}

Plain Finasteride gel and FSD loaded NLCs gel was evaluated for its occlusivity by measuring the percent water loss $[26,27] .50 \mathrm{ml}$ 
Distilled water was placed in different $100 \mathrm{ml}$ beakers. Each beaker was covered with a Whatman glass microfiber filter $(9.0 \mathrm{~cm})$. Test formulations were then applied on its surface. The beaker covered with filter in which no test formulation was applied served as a control for water loss. These beakers were then stored at $30 \pm 2{ }^{\circ} \mathrm{C} / 60 \pm 5 \%$ $\mathrm{RH}$ for a period of $48 \mathrm{~h}$. All the formulations were tested in triplicate keeping all the conditions constant. The samples were weighed after 6 , 24 and $48 \mathrm{~h}$, giving the water loss due to evaporation at each time (water flux through the filter paper). Beakers covered with filter paper but without applied sample served as reference values. Every experiment was performed in triplicate $(n=3)$. The occlusion factor $F$ was calculated according to the following equation:

$$
F=\frac{(A-B)}{A} \approx 10 \llbracket
$$

Where,

A is the water loss without sample (reference)

$\mathrm{B}$ is the water loss with sample

An occlusion factor of 0 means no occlusive effect compared to the reference and 100 is the maximum occlusion factor [28].

\section{In vitro drug release studies}

The In vitro release of FSD from FSD-NLC gel was evaluated using Franz diffusion cell (diffusion area $3.14 \mathrm{~cm}^{2}$; receptor volume of 13 $\mathrm{ml}$ ) at $32 \pm 0.5^{\circ} \mathrm{C}$ under sink condition. The dialysis membrane (pore size $0.22 \mu \mathrm{m}$ ) was mounted between the donor and receptor compartments. Freshly prepared phosphate buffer ( $\mathrm{pH} 7.4)$ was placed in receptor compartment. Medium was continuously stirred at $500 \mathrm{rpm}$. $1 \mathrm{~g}$ of gel formulation was then applied evenly on the surface of membrane in donor compartment. The aliquots from the receptor compartment were withdrawn at predetermined time interval $(1,2,3,4,5,6,7,8$ and 24h) and replaced with same volume of fresh medium. The FSD content from the withdrawn sample were estimated by UV spectrophotometrically after diluting with the solution. The experiment was conducted in triplicate. Percentage cumulative drug released at different time intervals was calculated.

\section{Release kinetics}

Data obtained from In vitro release studies were fitted to various kinetic equations to find out the mechanism of drug release from the SLN the dissolved amount of drug (M) is a function of the time $(t)$, or $\mathrm{M}=\mathrm{f}(\mathrm{t})$. In order to analyze the drug release mechanism, the data is fitted in zero-order, first-order, Higuchi model.

\section{In vitro heamolysis test}

For heamolytic studies, rat blood was collected in EDTA coated Eppendorf tubes and centrifuged at $-7^{\circ} \mathrm{C}, 4000 \mathrm{rpm}$ for $5 \mathrm{~min}$ (Remi
Laboratory instruments). The supernatant (plasma) was removed and the red blood cells (RBCs) were collected at the bottom of tubes. RBCs were washed thrice with normal saline $(0.9 \% \mathrm{w} / \mathrm{v} \mathrm{NaCl}$ solution). The cells were re-suspended in normal saline, pooled, diluted 10 times with normal saline and used for further studies. Test formulation $(1 \mathrm{ml})$ was incubated with $0.1 \mathrm{ml}$ aliquot of RBC stock dispersion at $37 \pm 0.5^{\circ} \mathrm{C}$ for $1 \mathrm{hr}$. To prepare the negative control, $0.1 \mathrm{ml}$ of RBC dispersion was incubated with $1.0 \mathrm{ml}$ of PBS $(\mathrm{pH} 7.4)$ and likewise, Triton X-100 solution $(5 \% \mathrm{~V} / \mathrm{V})$ was used in case of positive control. Test sample of FSD-NLC gel was prepared in normal saline. A volume of $0.5 \mathrm{ml}$ of test sample was added to the 4.5 $\mathrm{ml}$ of RBC suspension mixed gently and incubated at $37 \circ \mathrm{C}$ for $1 \mathrm{~h}$. After incubation, the samples were centrifuged at $1500 \mathrm{rpm}$ for 10 min (Remi Laboratory instruments) and the supernatants were analyzed for released oxyhemoglobin content spectrophotometrically at a wavelength of $546 \mathrm{~nm}$ (Jasco, Japan). Normal saline was taken as blank during analysis [29].

The \% hemolysis was estimated by following equation:

$$
\text { Heamolysis } \%=\frac{A s-A 0}{A 100-A 0} * 100
$$

Where,

AS= absorbance of test sample

$\mathrm{A}_{0}=$ absorbance of negative control (incubated with normal saline causing $0 \%$ heamolysis)

$\mathrm{A}_{100}=$ absorbance of positive control (incubated with Triton-X 100 causing 100\% heamolysis).

\section{Accelerated stability study}

Stability study was performed as per ICH guidelines Q1A (R2) for the optimized batch to determine the effect of presence of formulation additives on the stability of the drug and also to determine the physical stability of the formulation under accelerated storage conditions. The optimized batch was subjected to elevated temperature and humidity conditions of $(30 \pm 1$ ${ }^{\circ} \mathrm{C} / 65 \% \mathrm{RH}$ ). Samples were withdrawn at the end of 0, 30, 60 and 90 $\mathrm{d}$ and evaluated for active drug content, appearance and particle size [30].

\section{RESULTS AND DISCUSSION}

\section{Calibration curve of pure drug in methanol:}

The calibration curve for FSD in methanol follows Beers-Lambert's law. The graph of absorbance against concentration for FSD was found to be linear in the concentration range of $5-25 \mu \mathrm{g} / \mathrm{ml}$ at 255 $\mathrm{nm}$ as depicted in fig. 1.

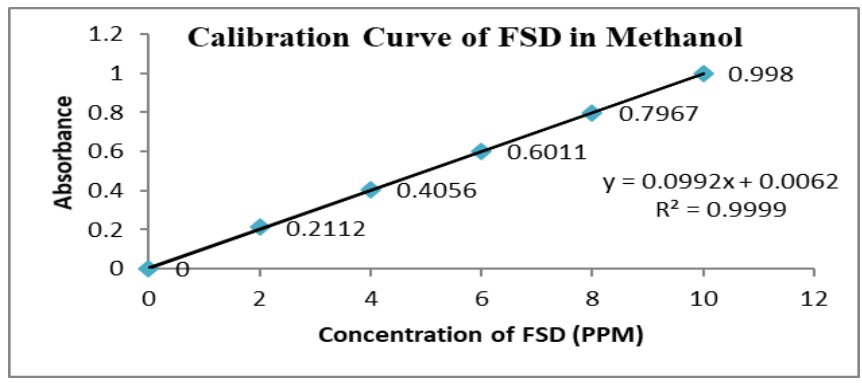

Fig. 1: Calibration curve of finasteride in methanol

\section{Screening of components}

\section{Solubility of the drug in solid lipids}

The results of solubility studies of FSD in solid lipid are shown. FSD showed greater solubility in GMS as shown in table 1. Also, properties of GMS like nontoxicity approved regulatory status and low cost favor its choice as a solid lipid. GMS is composed of stearic acid (C18) $>90 \%$ having melting point as $54.5-58.4{ }^{\circ} \mathrm{C}$ [31].

\section{Screening of surfactant and liquid lipid system \\ Solubility of drug in liquid lipid and surfactant}

Among oils and modified oils, Transcutol HP shown the highest solubility of FSD $420.65 \mathrm{mg} / \mathrm{ml}$ as shown in table 2. Tween 80 exhibited the highest solubility for FSD that is $415.28 \mathrm{mg} / \mathrm{ml}$ as shown in table 3 and was selected for further development. Tween 80 have HLB value of 15 and are comparatively safe, bio-compatible, less toxic and form micelles at lower concentrations. 
Table 1: Solubility of drug in solid lipids

\begin{tabular}{ll}
\hline Solid lipid & Solubility of FSD \\
\hline GMS & $\mathbf{9 4 1 . 3 6}$ \\
Beeswax, & 1606.65 \\
Carnauba wax, & 1510.41 \\
Stearic acid, & 2530 \\
\hline
\end{tabular}

FSD $=$ Finasteride, GMS $=$ Glyceryl Monostearate, (Values represent mean, $n=3$ )

Table 2: Solubility of drug in various liquid lipid (mg/ml)

\begin{tabular}{ll}
\hline Liquid lipid & Solubility of FSD \\
\hline Capmul MCM, & 340.83 \\
Oleic acid, & 125.10 \\
Transcutol HP & 420.65 \\
Captex & 151.82 \\
\hline
\end{tabular}

(Values represent mean, $\mathrm{n}=3$ )

Table 3: Solubility of FSD in various surfactant $(\mathrm{mg} / \mathrm{ml})$

\begin{tabular}{ll}
\hline Surfactant & Solubility of FSD \\
\hline Tween 80 & 415.18 \\
Tween 20 & 335.73 \\
Labrasol & 151.23 \\
Cremophore RH40 & 189.52 \\
\hline
\end{tabular}

FSD $=$ Finasteride, $($ Values represent mean, $n=3$ )

\section{Screening of process parameters \\ Partition behavior in various lipids}

Partition study was performed in various solid and liquid lipids. From the result shown in table 4, it was found that FSD had higher partitioning in Transcutol HP and GMS compared to other solid and liquid lipids respectively. This finding also supported the high solubility of the drug in GMS. Therefore, Transcutol HP and GMS were chosen as solid lipid and liquid lipid respectively for the development of NLCs.

Table 4: Partition coefficient of FSD in various solid and liquid lipid

\begin{tabular}{ll}
\hline Lipids & Partition coefficient of FSD \\
\hline Capmul MCM, & 2.4 \\
Oleic acid, & 1.2 \\
Transcutol HP & 3.0 \\
Captex & 0.89 \\
Glycerol monostearate (GMS), & 3.5 \\
Bees wax, & 2.6 \\
Carnauba wax, & 2.45 \\
Stearic acid, & 1.2 \\
\hline
\end{tabular}

(Values represent mean, $\mathrm{n}=3$ )

\section{Compatibility study of solid and liquid lipids}

Miscibility of solid lipid with liquid lipid was checked by compatibility study. The results of the compatibility study are shown in table 5 .

Table 5: Compatibility screening between solid and liquid lipid

\begin{tabular}{|c|c|c|c|c|c|}
\hline \multirow[t]{2}{*}{ Solid lipid } & \multirow[t]{2}{*}{ Liquid lipid } & \multirow[t]{2}{*}{ Ratio } & \multicolumn{3}{|c|}{ Phase separation after } \\
\hline & & & Solidification & $1 \mathrm{~h}$ & $24 \mathrm{~h}$ \\
\hline \multirow[t]{3}{*}{ GMS } & Transcutol HP & 09:01 & No & No & No \\
\hline & & 07:03 & No & No & No \\
\hline & & 03:01 & Yes & Yes & Yes \\
\hline
\end{tabular}

GMS=Glyceryl Monostearate

The mixtures were checked for phase separation immediately after solidification, after one hour and after 24h. Mixture with only one single phase was selected for further studies. GMS: Transcutol HP in the ratios of 9:1 and 7:3 showed no phase separation and hold their physical configuration throughout the $24 \mathrm{~h}$. But the same mixture in $3: 1$ ratio is seen in a semisolid state thus showing phase separation. The ratio of solid lipid: liquid lipid 7:3 was selected for further study since the bulk of solid lipid would have increased on the selection of the $9: 1$ ratio [32].

\section{Selection of formulation}

Several formulation batches were prepared and evaluated for particle size and stability studies. Based on result, NP3 batch was optimized and carried for further study.

Table 6: Data for evaluation of trial batches for particle size and stability

\begin{tabular}{lllll}
\hline Formulation Code & $\begin{array}{l}\text { GMS } \\
\text { (mg) }\end{array}$ & $\begin{array}{l}\text { Transcutol } \\
(\mathbf{m g})\end{array}$ & $\begin{array}{l}\text { Tween } \mathbf{8 0} \\
(\mathbf{m g})\end{array}$ & Particle size(nm) \\
\hline NP1 & 225 & 100 & 300 & $225 \pm 0.68$ \\
NP2 & 225 & 85 & 250 & $235 \pm 1.49$ \\
NP3 & 35 & 200 & $252.35 \pm 1.58$ \\
NP4 & 225 & $\mathbf{1 0 0}$ & $\mathbf{3 0 0}$ & $\mathbf{2 5 4 . 1 5} \pm \mathbf{0 . 7 9}$ \\
NP5 & $\mathbf{2 3 5}$ & 85 & 250 & $266.5 \pm 0.57$ \\
NP6 & 235 & 35 & 200 & $298.2 \pm 0.56$ \\
NP7 & 235 & 60 & 250 & $286.2 \pm 0.68$ \\
NP8 & 240 & 100 & 300 & $228.12 \pm 1.68$ \\
NP9 & 250 & 85 & 250 & $245.3 \pm 0.55$ \\
\hline
\end{tabular}

GMS= Glyceryl monostearate, (Values represent mean \pm SD, $n=3$ )

\section{Effect of sonication time on particle size and stability}

It was observed that with increase in sonication time from $10 \mathrm{~min}$ to 20 min there was no significant change in particle size and stability. So, for further studies $10 \mathrm{~min}$ as sonication time was selected.

\section{Optimization of trail batch}

For further optimization of NLC batch, following NP3 Batch was considered with concentrations of solid lipid GMS (235 mg), liquid lipid Transcutol HP (100 mg) and surfactant Tween 80 (300 mg) with sonication time of $10 \mathrm{~min}$ by evaluation of three parameters viz., Particle size, Entrapment efficiency and \% Drug loading.

In the above-shown data concentrations of solid and liquid lipid, surfactant concentration varied. It was observed that change in surfactant concentration affect particle size and stability of nanoparticles. At a high concentration of surfactant though the particle size low but does not stable for a longer time. 
Table 7: Effect of sonication time on particle size and stability

\begin{tabular}{llll}
\hline Sonication time (min) & Particle size $(\mathbf{n m})$ & Polydispersibility index & Stability \\
\hline 5 & $235.12 \pm 1.21$ & $0.74 \pm 0.42$ & Stable for $2-4$ d \\
$\mathbf{1 0}$ & $\mathbf{1 6 4 . 2 \pm 1 . 5 5}$ & $\mathbf{0 . 3 8 \pm 0 . 1 2}$ & \\
15 & $148.54 \pm 1.29$ & $0.23 \pm 0.09$ & Stable for more than 15 d \\
20 & $136.32 \pm 0.73$ & $0.09 \pm 0.10$ & \\
\hline
\end{tabular}

(Values represent mean $\pm \mathrm{SD}, \mathrm{n}=3$ )

Table 8: Optimization of trail batch

\begin{tabular}{lllll}
\hline $\begin{array}{l}\text { FSD } \\
\text { (mg) }\end{array}$ & $\begin{array}{l}\text { Solid lipid: liquid } \\
\text { lipid (mg) }\end{array}$ & Surfactant (mg) & $\begin{array}{l}\text { Particle size } \\
\text { (nm) }\end{array}$ & \% Entrapment efficiency \\
\hline $\mathbf{5}$ & $\mathbf{2 1 0 : 9 0}$ & $\mathbf{2 0 0}$ & $\mathbf{1 1 3 . 8 0 \pm 0 . 7 2}$ & $\mathbf{9 2 . 6 7 \pm 0 . 4 7}$ \\
5 & $210: 90$ & 300 & $96.1 \pm 0.73$ & $91.84 \pm 0.22$ \\
5 & $240: 60$ & 200 & $112.47 \pm 1.14$ & $89.38 \pm 0.42$ \\
5 & $240: 60$ & 400 & $98.1 \pm 1.19$ & $82.55 \pm 0.30$ \\
5 & $240: 60$ & 200 & $96.80 \pm 0.71$ & $85.62 \pm 0.33$ \\
5 & $270: 30$ & 300 & $112.75 \pm 0.51$ & $91.46 \pm 0.49$ \\
5 & $270: 30$ & 400 & $99.9 \pm 0.53$ & $86.41 \pm 0.48$ \\
5 & $270: 30$ & $97.81 \pm 0.50$ & $85.66 \pm 0.13$ \\
\hline
\end{tabular}

(Values represent mean $\pm \mathrm{SD}, \mathrm{n}=3$ )

Table 9: Composition of optimized formulation

\begin{tabular}{ll}
\hline Excipients & Quantity \\
\hline FSD & $5 \mathrm{mg}$ \\
GMS & $210 \mathrm{mg}$ \\
Transcutol HP & $90 \mathrm{mg}$ \\
Tween 80 & $200 \mathrm{mg}$ \\
Aqueous phase q. s. & $20 \mathrm{ml}$ \\
\hline
\end{tabular}

FSD= Finasteride, GMS= Glyceryl monostereate

Table 10: Mean particle size and polydispersibility index of formulation

\begin{tabular}{lll}
\hline Formulation & Particle size (nm) & PDI \\
\hline FSD-NLCs (a) & $113.80 \pm 1.02$ & $0.28 \pm 0.01$ \\
\hline
\end{tabular}

FSD $=$ Finasteride, $\mathrm{NLC}=$ Nano lipid carrier, $\mathrm{PDI}=$ Poly dispersibility Index, $($ Values represent $\mathrm{mean} \pm \mathrm{SD}, \mathrm{n}=3)$

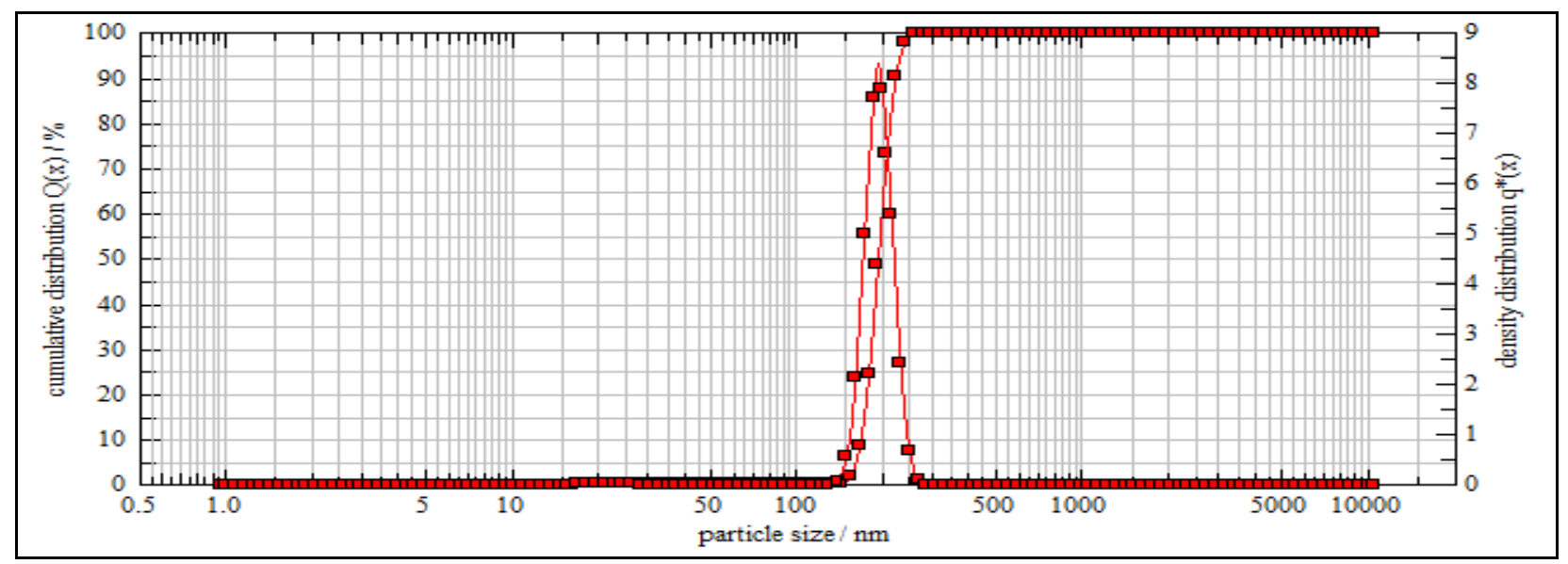

Fig. 2: Mean particle size of optimized formulation

\section{FT-IR spectroscopy}

FT-IR incompatibility study of drug and excipients FT-IR spectroscopy was carried out to test the compatibility of venlafaxine with chitosan in the formulation shown in fig. 1. FT-IR spectrum of venlafaxine showed the presence of characteristics band at 3317.87, $1533.42,1238.22,1036.92,960.77,823.21 \mathrm{~cm}-1$ due to $\mathrm{N}-\mathrm{H}$ stretching, $\mathrm{N}-\mathrm{H}$ bending, $\mathrm{O}-\mathrm{H}$ bending, C-O stretching, C-C stretching, and $\mathrm{C}-\mathrm{H}$ stretching. All these characteristics band also retained in 1:1 physical mixture of venlafaxine-chitosan are shown in fig. 1 . The results clearly revealed the compatibility of the drug with the excipients used in the formulation. It shows that there was no significant change in the chemical integrity of the dru FT-IR incompatibility study of drug and excipients FT-IR spectroscopy was carried out to test the compatibility of venlafaxine with chitosan in the formulation shown in fig. 1. FT-IR spectrum of venlafaxine 
showed the presence of characteristics band at 3317.87, 1533.42, $1238.22,1036.92,960.77,823.21 \mathrm{~cm}-1$ due to $\mathrm{N}-\mathrm{H}$ stretching, N-H bending, $\mathrm{O}-\mathrm{H}$ bending, $\mathrm{C}-\mathrm{O}$ stretching, $\mathrm{C}-\mathrm{C}$ stretching, and $\mathrm{C}-\mathrm{H}$ stretching. All these characteristics band also retained in 1:1 physical mixture of venlafaxine-chitosan are shown in fig. 1 . The results clearly revealed the compatibility of drug with the excipients used in the formulation. It shows that there was no significant change in the chemical integrity of the dru FTIR for the pure drug, Tween 80 and optimized formulation, is depicted in fig. 3 and 4 respectively. Finasteride IR spectra showed characteristic peaks at $3428 \mathrm{~cm}-1$ corresponding to the, amide groups, $2963 \mathrm{~cm}-1$ corresponding to $\mathrm{CH}_{3}$ group and $1688.37 \mathrm{~cm}^{-1}$ corresponding to $\mathrm{C}=0,1669.09 \mathrm{~cm}^{-1}$ corresponding to $\mathrm{C}=\mathrm{C}$. Tween- 80 shows many intense, sharp absorption peaks that are due to the different functional groups present in the molecules. Hydroxyl group $(-0 \mathrm{H})$ shows absorption band at $3454 \mathrm{~cm}^{-1}$, while the band at $2864 \mathrm{~cm}^{-1}$ is due to- $\mathrm{CH}_{2}$-stretching and at $2920 \mathrm{~cm}^{-1}$ is due to- $\mathrm{CH}_{3}$-stretching The band at $173 \mathrm{5m}{ }^{-1}$ can be attributed to $\mathrm{C}=0$ and the band at $1095 \mathrm{~cm}^{-1}$ is due to stretching of C-O-C. Finasteride optimum drug micronized formulation shown in fig. 5, confirms the compatibility of the drug with the excipients. It shows that there was no significant change in the chemical integrity of the drug. While considering the major peaks of the formulation spectrum, it was found to be closely related to the spectra of Tween 80 stating the superimposability of polymers with the drug.<smiles>CC(C)(C)NC(=O)[C@H]1CC[C@H]2[C@@H]3CC[C@H]4NC(=O)C=C[C@]4(C)[C@H]3CC[C@]12C</smiles>

Fig. 3: Structure of finasteride

FT-IR incompatibility study of drug and excipients FT-IR spectroscopy was carried out to test the compatibility of venlafaxine with chitosan in the formulation shown in fig. 1. FT-IR spectrum of venlafaxine showed the presence of characteristics band at 3317.87, 1533.42, 1238.22, 1036.92, 960.77, 823.21-«mdue to $\mathrm{N} \quad-\mathrm{H}$ stretching, $\mathrm{N}-\mathrm{H}$ bending, $\mathrm{O}-\mathrm{H}$ bending, $\mathrm{C}-\mathrm{O}$ stretching, $\mathrm{C}-\mathrm{C}$ stretching, and $\mathrm{C}-\mathrm{H}$ stretching. All these characteristics band also retained in 1:1 physical mixture of venlafaxine-chitosan are shown in fig. 1 . The results clearly revealed the compatibility of drug with the excipients used in the formulation. It shows that there was no significant change in the chemical integrity of the dru the broadband centered at $3,454 \mathrm{~cm}^{-1}$ is assigned to $0-\mathrm{H}$ stre.

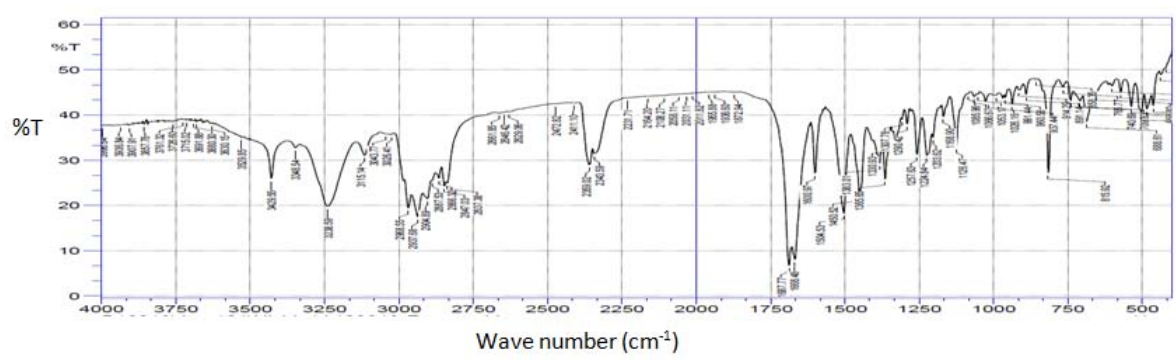

Fig. 4: FT IR spectrum of finasteride

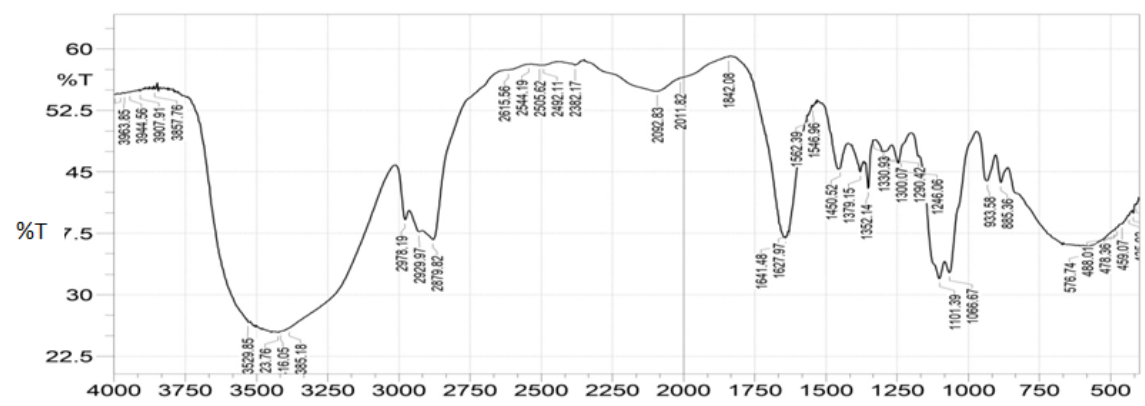

Wave number $\left(\mathrm{cm}^{-1}\right)$

Fig. 5: FT-IR spectrum of tween 80

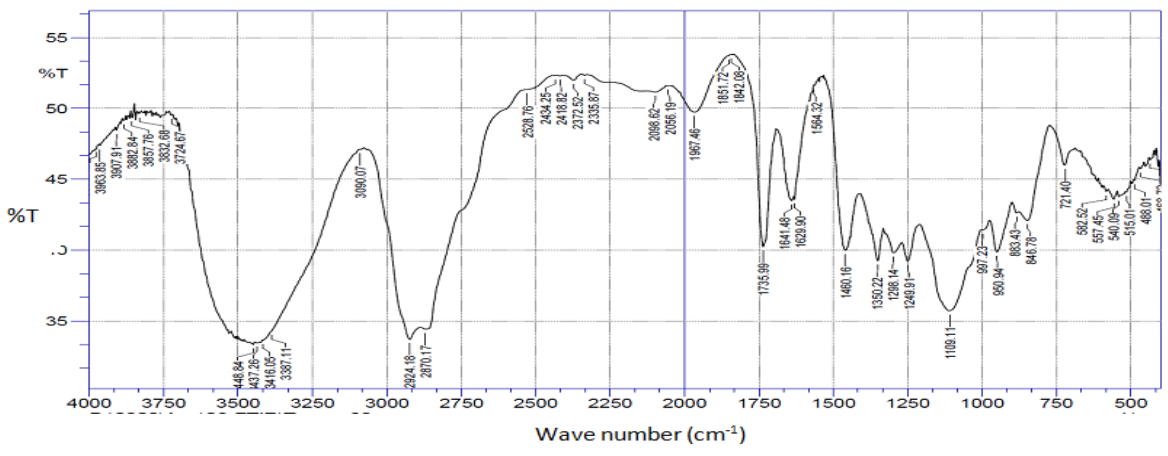

Fig. 6: FT-IR spectrum of finasteride formulation 
Table 11: Characteristic peaks observed in drug, excipient and formulation

\begin{tabular}{llll}
\hline Functional group & Observed value of finasteride $\left(\mathbf{c m}^{-1}\right)$ & Observed value of tween 80 (cm-1) & Observed value of formulation \\
\hline $\mathrm{N}-\mathrm{H}$ & $3428.81 \mathrm{~cm}^{-1}$ & - \\
$0-\mathrm{H}$ & - & 3454 & - \\
$\mathrm{CH} 3$ & $2936.09 \mathrm{~cm}^{-1}$ & $2920 \mathrm{~cm}-1$ & 3423 \\
$\mathrm{C}=0$ & $1688.37 \mathrm{~cm}^{-1}$ & $1724 \mathrm{~cm}^{-1}$ & $2929.97 \mathrm{~cm}^{-1}$ \\
$\mathrm{C}=\mathrm{C}$ & $1669.09 \mathrm{~cm}^{-1}$ & - & $1641 \mathrm{~cm}^{-1}$ \\
$\mathrm{C}-\mathrm{O}-\mathrm{C}$ & - & $1095 \mathrm{~cm}^{-1}$ & - \\
$\mathrm{CH} 2$ & - & $2864 \mathrm{~cm}^{-1}$ & $1101 \mathrm{~cm}^{-1}$ \\
\hline
\end{tabular}

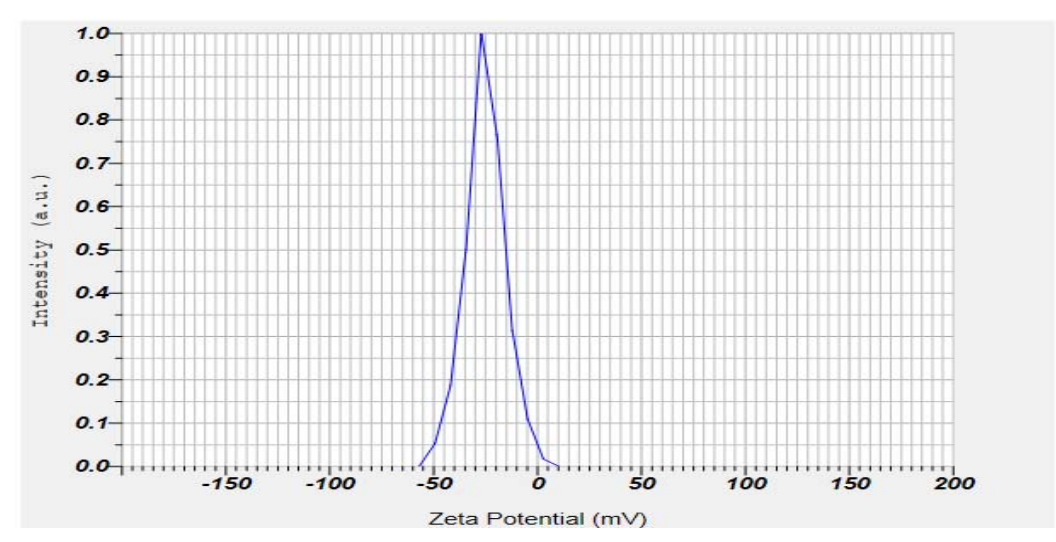

Fig. 7: Zeta potential of optimized formulation

\section{Zeta potential}

In general, zeta potential value of $\pm 20 \mathrm{mV}$ is sufficient for the stability of Nano suspension prepared using Tween 80 . The zeta potential of optimized Nano suspension was found to be $-25.2 \mathrm{mV}$, indicating that the prepared Nano suspension do not suffer from instability problems.

\section{Entrapment efficiency and drug loading}

The FSD-NLCs possessed high entrapment efficiency $92.67 \pm 0.47 \%$. The drug loading of TFM-NLCs was found to be $6.15 \pm 0.02 \%$.

\section{Thermodynamic stability}

\section{Effect of centrifugation to physical stability}

The physical instability of NLCs can be detected if there are phenomena of creaming, separation of oil phase or sedimentation of a component that has a high density occurred in NLCs. The formation of this phenomenon can be accelerated by using centrifugation. There was no such phenomenon observed for FSDNLCs after centrifugation at 13000 RPM for $30 \mathrm{~min}$ [33].

\section{Freeze-thaw cycle}

The freeze-thaw test was carried out to observe the physical stability of NLC during the fluctuation of temperature. One cycle of the freeze-thaw test consists of $48 \mathrm{~h}$ of storage at $4{ }^{\circ} \mathrm{C}$ and $48 \mathrm{~h}$ storage at $40{ }^{\circ} \mathrm{C}$. The parameter of particle size, PDI and phase separation of samples were measured during 4 cycles of the freezethaw test and the result is shown at table 12. At the end of first cycle, the diameter of nanoparticles was still in range of target. But the size of the nanoparticles was continuously increased after next cycle. But it was still in the Nano range and there was no phase separation observed till 6 cycles. This may be due to the kinetic stability of the formulation.

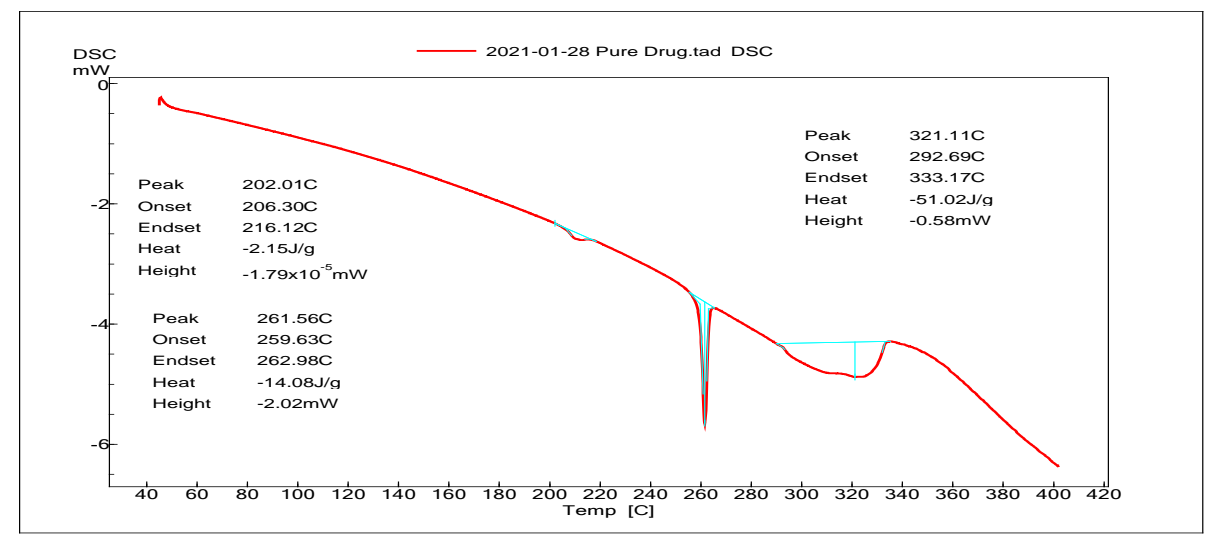

Fig. 8: DSC thermogram of finasteride drug

\section{Differential scanning calorimetry (DSC) studies}

Pure Finasteride drug showed a sharp endothermic peak at 259.63 ${ }^{\circ} \mathrm{C}$ and FSD-NLC showed a broader single endothermic heating peak at $35.03{ }^{\circ} \mathrm{C}$ as depicted in fig. 8 and 9. This result indicates that; the crystallinity degree was reduced when pure drug is converted to NLC. The reduced crystallinity of NLC may be related to the incorporation of drug in nanoparticle formulation. 


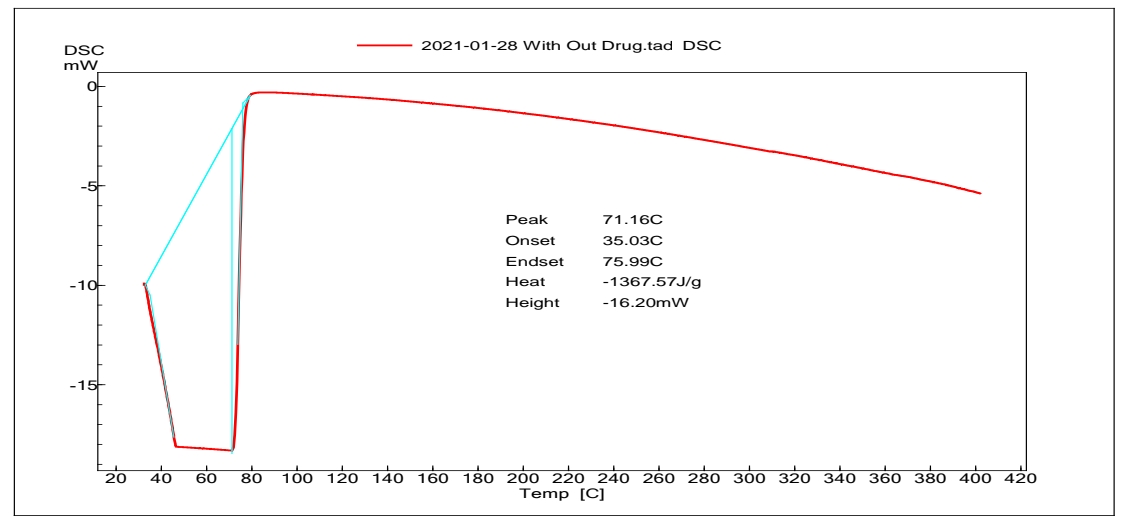

Fig. 9: DSC thermogram of finasteride formulation

Table 12: Particle size and polydispersibility index observed during freeze-thaw test

\begin{tabular}{llll}
\hline Cycles & Particle size $(\mathbf{n m})$ & PDI & Phase Separation \\
\hline 0 & $100.37 \pm 2.72$ & $0.25 \pm 0.01$ & No \\
1 & $142.48 \pm 1.97$ & $0.28 \pm 0.05$ & No \\
2 & $255.35 \pm 2.86$ & $0.31 \pm 0.05$ & No \\
3 & $325.45 \pm 5.89$ & $0.27 \pm 0.01$ & No \\
4 & $485.58 \pm 1.34$ & $0.31 \pm 0.05$ & No \\
5 & $654.81 \pm 2.98$ & $0.23 \pm 0.05$ & No \\
6 & $850.17 \pm 2.56$ & $0.29 \pm 0.05$ & No \\
\hline
\end{tabular}

$\mathrm{PDI}=$ Polydispersibility index, (Values represent mean $\pm \mathrm{SD}, \mathrm{n}=3$ )

\section{X-ray diffraction studies}

X-ray diffractometry can be useful for investigation of differences between the solid state and gel formed. Crystallinity had been interpreted by comparing the different peak heights in the diffraction pattern of the binary system with the reference. The Xray diffraction pattern of finasteride and Nano formulation prepared have been shown in fig 10 respectively. As seen in X-ray diffractogram of finasteride have the several sharp peaks at following diffraction angle $(2 \theta)$ in the range of $13.0^{\circ}-32.6^{\circ}$ suggesting that the drug is present in a crystalline form. A decrease in peak intensity formulation suggested that drug has been incorporated in to formulation and therefore lost its crystallinity.

A)

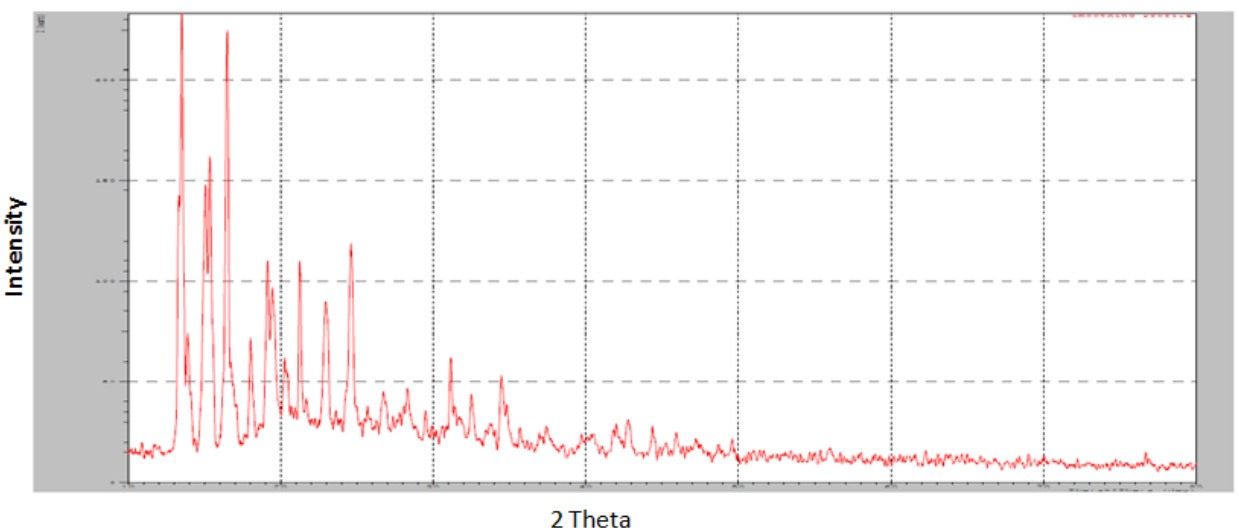

B)

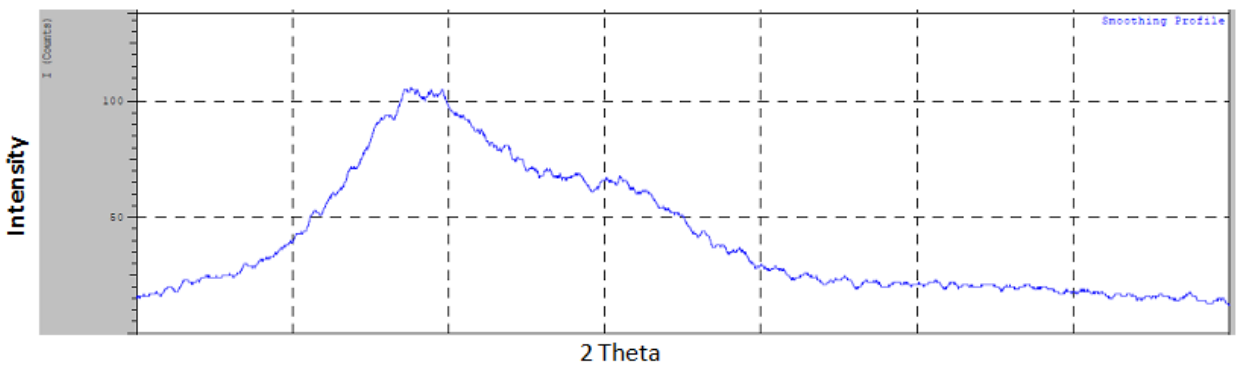

Fig. 10: X-Ray diffraction studies for A) FSD drug and B) Formulation 


\section{Scanning electron microscopy (SEM) analysis}

Optimized formulation was subjected for SEM study. SEM images in fig. 11, showed that FSD loaded NLCswere spherical in shapewith no aggregation. This indicates NLCs prepared by the probe sonication method was monodispersed. It further shows that FSD loaded NLCs is in nanosize range. Same results were found similar to the research study [34].
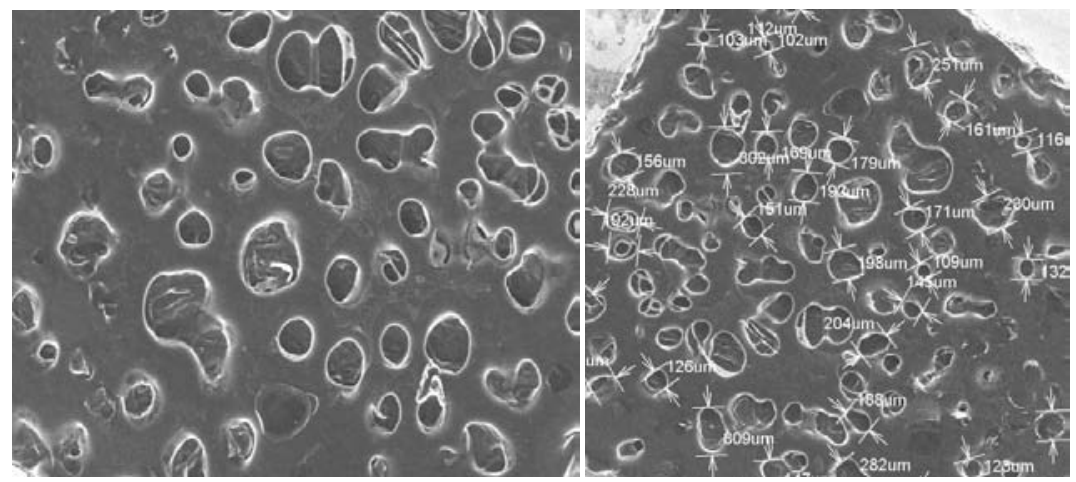

Fig. 11: Scanning electron microscopy images of finasteride nano lipid formulation

Table 13: Data for selection of suitable gelling agent

\begin{tabular}{lll}
\hline Batches & Gelling capacity & Observation \\
\hline $\mathrm{C}_{1}$ & Breaks immediately & Clear \\
$\mathrm{C}_{2}$ & Excellent & Clear \\
$\mathrm{C}_{3}$ & Excellent & Clear \\
$\mathrm{C}_{4}$ & Breaks immediately & Precipitation of drug \\
$\mathrm{C}_{5}$ & Good & Precipitation of drug \\
$\mathrm{C}_{6}$ & Good & Precipitation of drug \\
\hline
\end{tabular}

\section{Selection of gelling agent}

Trial batches of NLC gel was prepared using gelling agent as Carbopol 934P $(0.5,1,1.5 \%)$ (C1-C3) and Carbopol 974P (0.5, 1, $1.5 \%$ ) (C4-C6) which were selected from literature survey.

\section{Physicochemical characteristics of the gel}

\section{Determination of viscosity}

Viscosity study for all the batches were performed as mentioned in table 14. Viscosity is peculiar characteristic feature for gel like formulation. It is important for exhibiting adherence of formulation on to the skin and allowing drug release. As angular velocity increased formulation showed decrease in viscosity which suggests that the formulation have shear thinning characteristics [35]. C2 and C3 batches shown good viscosity but C3 batch having more viscosity which effects on drug release. C2 batch exhibited initial good viscosity and later on represented shear thinning characteristics. This property facilitates easy removal of the product from the container and for spreading of formulation on the skin. So C2 batch was selected for further study. Comparative study for all the trial batches is shown in fig. 12 .

Table 14: Viscosity study for trial batches

\begin{tabular}{|c|c|c|c|c|c|c|}
\hline RPM & C1 & $\mathrm{C} 2$ & C3 & C4 & $\mathrm{C5}$ & C6 \\
\hline 5 & 45600 & 47400 & 48510 & 28000 & 32475 & 36800 \\
\hline 10 & 28300 & 31750 & 34550 & 16000 & 24000 & 21120 \\
\hline 20 & 16446 & 12860 & 19260 & 8520 & 8900 & 16445 \\
\hline 40 & 8912 & 9700 & 9215 & 3200 & 5667 & 8500 \\
\hline 60 & 6215 & 7000 & 7806 & 1770 & 4600 & 5900 \\
\hline 80 & 3215 & 5445 & 4200 & 1413 & 2275 & 3563 \\
\hline 100 & 1958 & 3840 & 3927 & 1230 & 1489 & 1590 \\
\hline
\end{tabular}

RPM=Rotations per minute, (Values represent mean, $n=3$ )

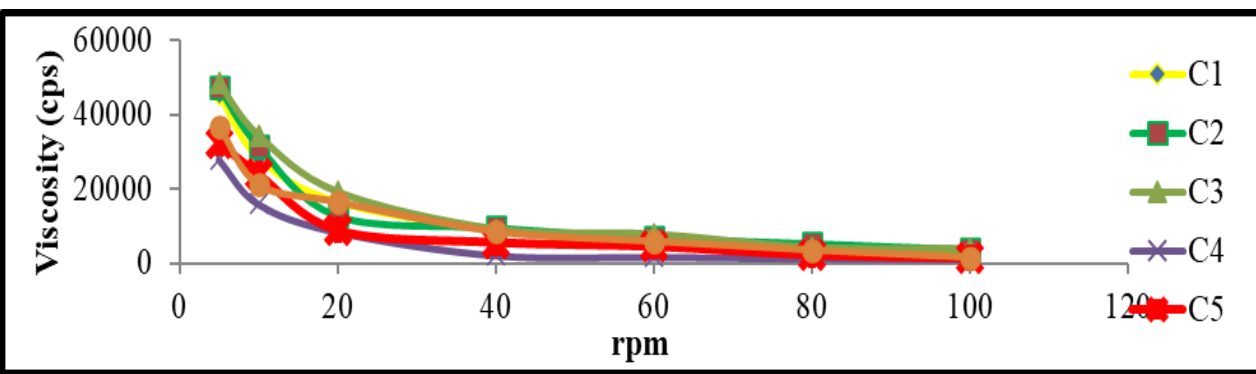

Fig. 12: Comparative study of viscosity for batches of carbopol 934P and 974P. Data represent mean (n=3) 
Table 15: Physical appearance and homogeneity

\begin{tabular}{ll}
\hline Parameters & Observation \\
\hline Appearance & Whitish \\
Consistency & Smooth \\
Grittiness & None \\
Uniformity & Good \\
\hline
\end{tabular}

\section{Determination of $\mathbf{p H}$}

The $\mathrm{pH}$ of gel formulation was found to be in the range of 6.5-6.8 and which was near to the physiological $\mathrm{pH}$ of the skin. Hence it was concluded that the gel formulation was safe to use topically.

\section{Drug content uniformity}

Drug content was determined by UV analysis at $255 \mathrm{~nm}$ which was found to be $91.25 \pm 0.9 \%$.

\section{Spreadability study of gel}

Spreadabilty of formulations was done by applying weight in increasing order on to the formulation applied and an increase in the diameter was measured. The FSD-NLC gel formulation indicated a good spreadability that would guarantee the practicability to skin application. The spreadability of gel formulation was found in the range of $6.7 \mathrm{~cm} / \mathrm{sec}$ which can be easily applied to skin and result was found to be similar to results mentioned in reference [36].

\section{In vitro occlusivity test}

The occlusion factor was the main characteristics of skin hydration because nanoparticles may form a film on the skin avoiding loss of water Therefore, occlusive nanoparticles contribute to increase the time of contact of the formulation on to the skin favoring a prolonged effect of the FSD. Occlusion factor (F) for Plain FSD gel and FSD loaded NLCs gel was found to be $71.24 \pm 1.23$ and $92.58 \pm 1.98$ at the end of $48 \mathrm{~h}$.

It was reported that an $\mathrm{F}$ value of 0 means no occlusive effect compared to the reference, while an $\mathrm{F}$ value of 100 means maximum occlusiveness. The comparative study between the Plain FSD gel and FSD loaded NLC gel, the obtained result showed more occlusivity in FSD-NLC gel as compared to Plain FSD gel and both showed the significant prevention of water loss at the end to $48 \mathrm{~h}$.

\section{In vitro drug release study}

The ability of gel formulation to deliver FSD was examined by determining the drug release rate. Table 16 and fig. 13 shows the cumulative percentage release of FSD from FSD-NLCs gel and plain gel at different time intervals. This result clearly indicated that the amount of FSD penetrating through the dialysis membrane (pore size $0.22 \mu \mathrm{m}$ ) from the NLC gel was significantly much higher than the amount of FSD permeating from the FSD plain gel at $24 \mathrm{~h}$. The enhanced skin permeation of the FSD loaded in the NLC gel is mainly due to the increased surface area and smaller size of the particles that interface with skin corneocytes, superior skin occlusion characteristics, and more effective hydration of the stratum corneum as compared with other dosage forms [37].

Table 16: In vitro drug release study for FSD nanogel and plain gel

\begin{tabular}{lll}
\hline Time (h) & Cumulative \% release from FSD-NLC gel $(\boldsymbol{\mu g})$ & Cumulative $\%$ release from plain FSD gel $(\boldsymbol{\mu}$ ) \\
\hline 1 & $220.62 \pm 1.42$ & $166.5 \pm 0.49$ \\
2 & $265.1 \pm 1.41$ & $217.7 \pm 2.05$ \\
3 & $302.36 \pm 1.60$ & $253.7 \pm 1.26$ \\
4 & $372.47 \pm 1.20$ & $299.2 \pm 4.41$ \\
5 & $463.9 \pm 0.78$ & $346.5 \pm 1.51$ \\
6 & $516.4 \pm 1.42$ & $396.2 \pm 1.49$ \\
7 & $521.77 \pm 0.69$ & $437.15 \pm 0.75$ \\
8 & $555.6 \pm 1.93$ & $490.03 \pm 1.15$ \\
\hline
\end{tabular}

FSD: Finasteride, NLC: Nano lipid carrier, (Values represent mean $\pm S D, n=3$ )

\section{In Vitro Drug Release}

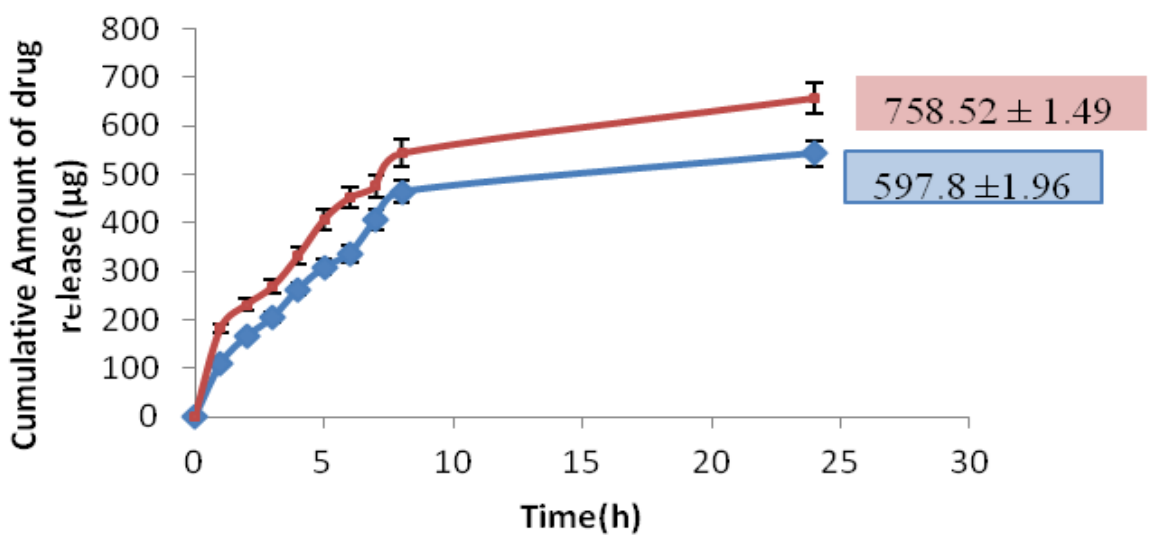

Fig. 13: In vitro drug release of FSD gel depicted in red and plain gel depicted in blue. Data represents mean \pm SD, SD values are given as error bars

\section{In vitro heamolysis study}

Though heamolytic toxicity is essential to be performed for parenteral nanoparticles, we conducted the experiment to check its safety towards normal human cells. In vitro heamolysis of the isolated erythrocytes on incubation with FSD-NLC gel was evaluated. In comparison to Triton X-100, the FSD-NLC gel formulation showed only $0.48 \%$ heamolysis, indicating the safety as well as compatibility towards normal human cells as well as compatibility [38]. 


\section{Release kinetics}

It was evident from data depicted from table 17, that the Higuchi diffusion model was best fitted for FSD release from NLC gel with a higher correlation coefficient $\left(R^{2}=0.9944\right)$. The previous result is in agreement with many studies which reported that drug-loaded NLC provides a controlled release pattern following Higuchi's square root model which indicates drug release by diffusion mechanisam. Plain FSD gel follows Higuchi's square root model with a higher correlation coefficient $\left(\mathrm{R}^{2}=0.9979\right)$ [39].

Table 17: Data for kinetic models for nanogel and plain gel

\begin{tabular}{llll}
\hline S. No. & Kinetic models & r $^{2}$ FSD-NLC gel & r $^{2}$ Plain FSD gel \\
\hline 1. & Zero-order & 0.8356 & 0.9449 \\
2. & First-order & 0.3983 & 0.5833 \\
3. & Higuchi & 0.9944 & 0.9979 \\
4. & Hixon-Crowel cube root & 0.3869 & 0.5698 \\
5. & Korsemeyer-Peppas & 0.9397 & 0.9137 \\
\hline
\end{tabular}

$\mathrm{R}^{2}$ : Regression value, FSD: Finasteride, NLC: Nanolipid carrier

\section{Accelerated stability study}

FSD-NLC gel was subjected for stability testing for 3 mo in order to check the possibility of drug degradation or any possible development of instability in the formulation. The results suggest that there was no significant difference in values of Entrapment efficiency, drug content and physical characteristics of formulation also remained unchanged suggesting that formulation was stable under given conditions. The result of accelerated stability study is given in table 18.

Table 18: Accelerated stability study results

\begin{tabular}{|c|c|c|c|c|}
\hline Months & Temperature & Appearance & Entrapment efficiency (\%) & Drug content (\%) \\
\hline $1^{\text {st }}$ & $40^{\circ} \mathrm{C} \pm 2{ }^{\circ} \mathrm{C} / 75 \% \mathrm{RH} \pm 5 \% \mathrm{RH}$ & No change & $95.37 \pm 0.50$ & $92.01 \pm 0.66$ \\
\hline $2^{\text {nd }}$ & & & $94.86 \pm 1.10$ & $91.54 \pm 0.51$ \\
\hline $3^{\text {rd }}$ & & & $93.97 \pm 0.76$ & $90.02 \pm 0.76$ \\
\hline
\end{tabular}

(Values represent mean $\pm \mathrm{SD}, \mathrm{n}=3$ )

\section{CONCLUSION}

Finasteride nanoparticles were prepared by the ultra-sonication method and successfully incorporated into the topical gel. The optimized NP3 trail exhibited spherical shape with a mean diameter of $113.80 \pm 0.72$, the polydispersity of $0.28 \pm 0.01$, zeta potential of$25.2 \mathrm{mV}$, drug entrapment efficiency of $92.67 \pm 0.47 \%$, and drug loading of $6.15 \pm 0.02 \%$. Storage stability studies demonstrated that the particle size and entrapment efficiency of the FSD-NLCs were not changed during $3 \mathrm{mo}$ both at $4{ }^{\circ} \mathrm{C}$ and room temperature. Among the different batches of NLC gel prepared using gelling agent as Carbopol 934P, C2 batch was selected, based on $\mathrm{pH}$ (6.5-6.8), drug content $(91.25 \pm 0.9 \%)$, spreadability $(6.7 \mathrm{~cm} / \mathrm{sec})$ and has desired physicochemical properties required for topical gel. The percent cumulative drug release for $\mathrm{C} 2$ batch was found to be $758.52 \pm 1.49$ $\mu \mathrm{g}$ at $24 \mathrm{~h}$ which is quite higher. In conclusion, the prepared nanogel of finasteride was stable and could be used with promising potential for the treatment of Androgenetic Alopecia.

\section{ACKNOWLEDGEMENT}

Authors would like to thank the Principal and Management, Department of Pharmacy, University College of Technology, Osmania University for extending the support to carry out the research work, and the authors are thankful to D. Hari Narayana, CEO, Nishka Laboratories for helping us in carrying out formulation and evaluation studies with numerous trails.

\section{FUNDING}

Nil

\section{AUTHORS CONTRIBUTIONS}

All the authors have contributed equally.

\section{CONFLICTS OF INTERESTS}

The authors declare that the research was conducted in the absence of any commercial or financial relationships that could be construed as a potential conflict of interest.

\section{REFERENCES}

1. Salisbury BH, Tadi P. 5 Alpha reductase inhibitors. Treasure Island (FL): StatPearls Publishers; 2020.

2. Divya S, Shyam SR. A model for docking finasteride to $5 \alpha$ reductase. Online J Bio Inform 2019;20:182-93.

3. Lee SW, Juhasz M, Mobasher P, Ekelem C, Mesinkovska NAA. Systematic review of topical finasteride in the treatment of androgenetic alopecia in men and women. J Drugs Dermatol 2018;17:457-63.

4. Roque LV, Dias IS, Cruz N, Rebelo A, Roberto A, Rijo P, et al. Design of finasteride-loaded nanoparticles for potential treatment of alopecia. Skin Pharmacol Physiol 2017;30:197-204.

5. Lademann J, Richter H, Teichmann A, Otberg N, Blume Peytavi U, Luengo J, et al. Nanoparticles-an efficient carrier for drug delivery into the hair follicles. Eur J Pharm Biopharm 2007;66:159-64.

6. Ahlin GP, Kristl J. The manufacturing techniques of drug-loaded polymeric nanoparticles from preformed polymers. J Microencapsulation 2011;28:323-35.

7. Couvreur P, Barratt G, Fattal E, Legrand P, Vauthier C. Nanocapsule technology: a review. Crit Rev Ther Drug Carrier Syst 2002;19:99-134

8. Reis CP, Roque LV, Baptista M, Rijo P. Innovative formulation of nystatin particulate systems in toothpaste for candidiasis treatment. Pharm Dev Technol 2016;21:282-7.

9. Madheswaran T, Baskaran R, Thapa RK, Rhyu JY, Choi HY, Kim $\mathrm{JO}$, et al. Design and in vitro evaluation of finasteride-loaded liquid crystalline nanoparticles for topical delivery. AAPS PharmSciTech 2013;14:45-52.

10. Franklin SJ, Younis US, Myrdal PB. Estimating the aqueous solubility of pharmaceutical hydrates. J Pharm Sci 2015;105:1914-9.

11. Sharma A, Baldi A. Nanostructured lipid carriers: a review. J Dev Drugs 2018;7:2.

12. Priyanka J, Parshotam M, Senshang L. Transdermal delivery of diclofenac using water-in-oil microemulsion: formulation and mechanistic approach of drug skin permeation. Pharm Dev Technol 2014;19:373-84. 
13. Ranpise NS, Korabu SS, Ghodake VN. Second generation lipid nanoparticles (NLC) as an oral drug carrier for delivery of lercanidipine hydrochloride. Colloids Surf B 2014;116:81-7.

14. Chen CC, Tsai TH, Huang ZR, Fang JY. Effects of lipophilic emulsifiers on the oral administration of lovastatin from nanostructured lipid carriers: physicochemical characterization and pharmacokinetics. Eur J Pharm Biopharm 2010;74:474-82.

15. Ranpise NS, Korabu SS, Ghodake VN. Second-generation lipid nanoparticles (NLC) as an oral drug carrier for delivery of lercanidipine hydrochloride. Colloids Surf B 2014;116:81-7.

16. Slavomira D, Joana A, Garcia ML, Erik R, Eliana BS. Formulating fluticasone propionate in novel PEG-containing nanostructured lipid carriers (PEG-NLC). Colloids Surf B 2010;75:538-42.

17. Nasr M, Mansour S, Mortada ND, El Shamy AA. Lipospheres as carriers for topical delivery of aceclofenac: preparation, characterization and in vivo evaluation. AAPS PharmSciTech 2008;9:154-62.

18. Patel D, Dasgupta S, Dey S, Roja Ramani Y, Ray S, Mazumder B. Nanostructured lipid carriers (NLC)-based gel for the topical delivery of aceclofenac: preparation, characterization, and in vivo evaluation. Sci Pharm 2012;80:749-64.

19. Bhaskar K, Anbu J, Ravichandiran V, Venkateswarlu V, Rao YM. Lipid nanoparticles for transdermal delivery of flurbiprofen: formulation, in vitro, ex vivo and in vivo studies. Lipids Health Dis 2009;8:6.

20. Malgope A, Murthy P, Ramani R, Dey S. Development of nanoemulsion as carrier for transdermal delivery of valsartan. Int J Pharm Chem Sci 2013;2:1655-65.

21. Kotta S, Khan AW, Ansari S, Sharma R, Ali J. Formulation of nano-emulsion: a comparison between phase inversion composition method and high-pressure homogenization method. Drug Delivery 2015;22:455-66.

22. Meghana G, VVSNR K, Talluri S, Gunda R, Channareddy S, Ganesh G. Formulation and evaluation of tolnaftate loaded topical liposomal gel for effective skin drug delivery to treat fungal diseases. J Chem Pharm Res 2014;6:856-66.

23. Jannin V, Musakhanian J, Marchaud D. Approaches for the development of solid and semisolid lipid-based formulations. Adv Drug Delivery Rev 2008;60:734-46.

24. Inamdar Y, Rane B, Jain A. Preparation and Evaluation of beta sitosterol nanogel: a carrier design for targeted drug delivery system. Asian J Pharm Res Dev 2018;6:81-7.

25. Bhimashankar M, Sachin K, Kakasaheb RM. Formulation and evaluation of topical liposomal gel for fluconazole. Indian J Pharm Educ Res 2010;44:324-33.
26. Chen MX, Alexander KS, Baki G. Formulation and evaluation of antibacterial creams and gels containing metal ions for topical application. J Pharm (Cairo) 2016;5754349.

27. Maru AD, Lahoti SR. Formulation and evaluation of moisturizing cream containing sunflower wax. Int J Pharm Pharm Sci 2018;10:54-9.

28. Souto EB, Wissing SA, Barbosa CM, Muller RH. Development of controlled release formulation based on SLN and NLC for topical clotrimazole delivery. Int J Pharm 2004;278:71-7.

29. Jannin V, Musakhanian J, Marchaud D. Approaches for the development of solid and semisolid lipid-based formulations. Adv Drug Delivery Rev 2008;60:734-46.

30. Pund S, Pawar S, Gangurde S, Divate D. Transcutaneous delivery of leflunomide nanoemulgel: mechanistic investigation into physicomechanical characteristics, in vitro anti-psoriatic and anti-melanoma activity. Int J Pharm 2015;487:148-56.

31. Singh H, Gupta RD, Gautam G. Formulation development, characterization and in vitro-in vivo study of antihyperlipidemic drug rosuvastatin calcium-solid lipid nanoparticles. Asian J Pharm Clin Res 2018;11:436-43,

32. Khalil M, Ismail E, El-Baghdady K, Doaa M. Green synthesis of silver nanoparticles using olive leaf extract and its antibacterial activity. Arabian J Chem 2013;7:1131-9.

33. Patel D, Dasgupta S, Dey S, Roja Ramani Y, Ray S, Mazumder B. Nanostructured lipid carriers (NLC)-based gel for the topical delivery of aceclofenac: preparation, characterization, and in vivo evaluation. Sci Pharm 2012;80:749-64.

34. Pamudji JS, Mauludin R, Indriani N. Development of nanostructured lipid carrier formulation containing of retinyl palmitate. Int J Pharm Pharm Sci 2016;8:256-60.

35. Garcia Negrete CA, Jimenez de Haro MC, Blasco J, Soto M Fernandez A. STEM-in-SEM high resolution imaging of gold nanoparticles and bivalve tissues in bioaccumulation experiments. Analyst 2015;140:3082-9.

36. Khurana S, Bedi PMS, Jain NK. Preparation and evaluation of solid lipid nanoparticles based nanogel for dermal delivery of meloxicam. Chem Phys Lipids 2013;175:65-72.

37. Rajinikanth PS, Chellian J. Development and evaluation of nanostructured lipid carrier-based hydrogel for topical delivery of 5-fluorouracil. Int J Nanomed 2016;11:5067-77.

38. Pooja D, Panyaram S, Kulhari H, Rachamalla SS, Sistla R. Xanthan gum stabilized gold nanoparticles: characterization, biocompatibility, stability and cytotoxicity. Carbohydr Polym 2014;110:1-9.

39. Inayathulla, Goudanavar P, Ali M, Din Wani Su, Sreeharsha N. Formulation and evaluation of in-situ gel containing linezolid in the treatment of periodontitis. Int. J Appl Pharm 2021;13:79-86. 